\title{
TRENDS TOWARD MECHANIZATION OF FOREST FIRE CONTROL
}

\author{
By Roy Headley, \\ Chief, Division of Fire Control \\ U. S. Department of Agriculture, Forest Service
}

$\mathrm{T}$

HIRTY years ago fires were discovered by chance and located by guess.

Travel was on foot or by the aid of horse power or canoe. Fires were

suppressed by main strength and awkwardness-if at all. There were

only hand tools to work with, and these were not specialized fire fighting tools. They were merely the common tools of the woodsman taken over by this new adventure of keeping our wild land productive by protecting it from fire.

Mechanization of fire control got a late start, but once the transformation began, it proceeded at a rapid pace. The accumulated machines and machine technologies of the past century were ready to be drawn upon by the ingenuity of fire control men.

Today there is a bewildering array of machines and mechanical gadgets to aid in the struggle with fire. The judgment of executives is guided by a long list of instruments employed to determine the true fire danger at any time by measurement and integration of the moisture content of forest fuels, moisture in the air, wind and temperature.

To serve the lookout man in discovering and locating fires, there is a long list of instruments of more or less precision.

Communication when fires are detected as well as between executives in charge of the war-like job of corralling a going fire, is provided by telephones and the miracle of modern fire control radio. The National Forests in the United States use over 2,700 specially designed, low-cost, two-way radios, transmitting voice as well as code. This is said to be the largest number of radios used by any one agency in the country.

The horse and mule are still important to fire control transportation but machines are increasingly used to whirl them to the end of the road. The latest development is a huge cab-over-engine truck which hauls 9 mules-a complete packing unit. The power plant of the vehicle is so strong that mules ride to the end of the road at 60 miles an hour on level roads and 30 miles per hour up a 6 per cent. grade. The mules must wear masks to protect them from air pressure and wind-borne dust and gravel. 
The airplane supplies the most dramatic touch to fire control transportation of today. This machine got a bad start with us and discovery of its major function in fire control was long delayed. It was first tried at fire detection. It was regarded as a competitor of lookout men stationed on towers or mountain peaks. This was a fallacy which clear thinking should have recognized as such without the necessity of long experimentation. There is no acceptable substitute for detection by trained men located at lookout stations.

Transportation is the true role of aircraft in fire control. One hundred and twelve tons of supplies and equipment were dropped at fire camps on one large fire last summer. Hundreds of burlap parachutes costing less than a dollar each were used. Some dropping is still done without parachutes by the tight package method developed in Idaho and Montana, but the trend is definitely toward these simple home-made parachutes with which fragile materials, such as cases of eggs and portable pumpers can be dropped without damage.

Fire fighters are of course moved by air when that will help. Sixty-six landing fields have already been carved out in mountain areas, and many lakes are large enough to permit seaplanes to land. But at best, the number of landing fields and lakes is not great enough to permit aircraft to serve largely in transportation of fire fighters with conventional planes of today. It will be a different story when rotary winged ships are produced with enough useful load capacity to be interesting. When that time comes, the ridges and narrow canyon bottoms, as well as the flat woods, will soon be dotted with little fields usable by this type of ship. A real revolution will then be in order in the placement and transportation of men used on fire suppression.

Whether aircraft can be used to drop chemicals, explosives or water on small fires to keep them small until ground forces can reach them, is still a matter of patient experimentation. At any rate, the only airplane owned by the National Forest Branch of the Forest Service is dedicated to this experimental venture and work will be kept up until we can give definite answers to the questions about the possible use of aircraft in this way.

For use in the suppression of fires, many machines have been tried and found wanting; but a good many have stood the test and now find varying degrees of favor.

Close to a hundred tank trucks are now used chiefly in California and the Gulf States. An initial purchase has been made of two Ford tank trucks with Marmon-Herrington four wheel drive mechanism, for use in the Gulf 
States. These four wheel drive rigs are almost equal to track laying tractors for negotiating swamps, mud and sand. They have also the advantage of good speed while on roads. No desirable track laying tractor has been discovered with alternate high speed for road travel and low speed with high draw bar pull for use after the job is reached. A tractor of this type by Marmon-Herrington which promised to meet the need had to yield to the four wheel drive truck when subjected to comparative test.

Portions of the National Forest are covered with chaparral-a dense, almost impenetrable growth of brush species which might well be called botanical barbed wire. Foresters with experience in trying to crawl through these jungles are much elated when it is possible to fight chaparral fires with the standard tractor-trailbuilder developed years ago by the Forest Service for road construction purposes but used now for fire fighting. This rig has a power controlled blade mounted at an angle on the front of a tractor, the tractor usually being of 55 horsepower capacity. They cannot work on slopes above 45 per cent.; but under that limit, these machines are an answer to a fire fighter's prayer in dense brush, slash or windfalls which are not too large to be shoved around or broken. These machines can be used in a swinging motion to push in the flaming edge of the fire-so long as the operator can stand the heat, smoke and risk that a flare-up may endanger his life.

The "brushbuster" which is favored in places is similar in design but has a V-shaped blade (like a snow plow) in place of the trail-builder straight blade mounted at an angle. As a clearing tool when the growth and debris is not too heavy, the brushbuster can drive ahead continuously without side casting and backing up in the movement characteristic of the trailbuilder machine.

Various plows have been designed to be drawn by tractors. Disc plows jump out too easily when small logs and heavy brush stools are encountered. Most used is some form of the Deschutes plow which is a double mold board affair with a Roman nosed point to lift the plow over rocks and roots which cannot be penetrated. Years of experimentation have failed to find a final answer to such questions as the best over-all width for the plow bottom and the mold boards, the best form of points to use and the exact form to give the beam to get the least clogging, the most strength and the lightest weight. However, these are good power tools which have been used to construct many hundreds of miles of control line.

All these heavy machines have one serious drawback. They are heavy. To transport them to a fire requires still more heavy equipment which too often is slow as well as heavy. There is no help for this when the job to be 
done requires heavy machinery-as in the case of control line in chaparral or logging slash. But much control line construction does not require a machine of great weight. For this type of work our latest power driven tool has been developed. This is the Bosworth Trencher. Forty of these machines are being made up for National Forest use next summer. The cost with the Bendix outboard motor now being used, is about $\$ 350$ each, which is small change compared to the cost of trailbuilders and similar machines, together with the rolling equipment required to move them. The total weight of the Bosworth Trencher with Bendix engine is 96 pounds. It is not selfpropelling because we prefer to use man-power for that purpose in order to keep the weight of the machine down and put all our available engine power into the hammers. On grades, from one to five men may be required on the rope used to tow the machine up hill and hold it back going down hill. The machine does its work by centrifugal force applied through swinging hammers attached to a hub which can be adjusted to throw the stream of dust and litter in any desired direction. The hammers revolve at 800 revolutions per minute. These hammers are made of specially hardened steel to withstand severe wear and abuse. Two lengths of hammer hubs have been designed and tested. The average width of trench produced is $111 / 2$ inches with the shorter hammer hub set at a 45 degree angle, or 14 inches with the longer hub set at the same angle. Except in extreme conditions these widths are sufficient from which to backfire. When required by extreme depth of duff or height of dry grass, two or more machines can be operated in tandem formation to get any desired trench width.

While the machine is distinctly not a clearing tool, it does surprisingly well in limber brush up to two feet in height. It also does an amazingly good job in hammering its way through roots up to nearly an inch in diameter.

Under test, the machine surprised everyone with what it would do in the rooty white pine litter of North Idaho. It marches with ease through needles and litter characteristic of a ponderosa pine stand. On grass fires the heavy stream of dust from the hammers does an amazing job of knocking down the flames, and if the growth is not too heavy, actually extinguishes the fire.

Suppression of forest fires is notoriously the orphan child of forest protection. Speed in control line construction is the weakest point in that orphan child. This machine drives right at this weak point and promises a rate of speed in fire line construction not hitherto attainable. An output of one to three chains of fire line per man day is about all we seem to get under conventional practice with hand tools on the larger fires. With this machine, 
all the tests and conversation about rate of output are in terms of chains per minute.

One of the advantages of the Bosworth Trencher is that it is so light and so easily carried in most any kind of a vehicle. Two of these machines can be lashed in the body of a pickup truck with the most of the space still left for other tools and supplies. The ease with which the machine can be trans. ported means that it has an excellent chance to arrive at a fire with the first man to reach it.

Like all other machines, this one has its drawbacks. One faulty item is the engine. The two-cylinder, two-cycle, verticle drive, air-cooled, four-horse power engine now being used is too low powered for the best all-around results. Our trouble is that we have been unable to obtain any air-cooled engine of the size we really need. We would be willing to increase the total weight of the machine up to 126 pounds if by so doing we could add measurably to the horsepower behind the hammers.

Another serious drawback is that the machine is hard on the operator. It will probably prove wise to change operators every five or ten minutes. Even with well designed shoulder straps to make it easier for the operator to carry the load, and with men pulling on the tow rope ahead, the operator has a hard time. In addition, when the drafts are unfavorable, the cloud of dust and dirt is quite obnoxious.

If in some way a somewhat larger engine can be found for the Bosworth Trencher, the same engine will probably solve the problem of the power saw for high speed clearing of logs encountered on a control line. National Forest organizations have done their share of experimenting with power driven saws without as yet finding any that is really satisfactory. This tool is much needed however, and it is only a matter of time until some satisfactory design of saw and engine will become available.

In the development of power driven tools for fire control purposes, it is necessary to maintain our sense of balance. Important as such tools are in multiplying the potentialities of men assembled to fight a forest fire, it is necessary to remember that all of these tools have their limitations and that in the last analysis there are many instances when no power driven tools can be employed. It so happens that some of the worst fires of the past year on the National Forests occurred in country so rough that no power driven tool which it is now possible to conceive could be employed on the control lines. In such instances and in many other comparable ones we must fall back on man power and the skill which is needed in managing men on the difficult job of corralling forest fires. 